\title{
Os olhares dos discentes do Mestrado Profissional de Educação de Jovens e Adultos sobre a inclusão no ambiente escolar da EJA
}

\begin{abstract}
Resumo: Este estudo parte da necessidade da discussão acerca da formação de professores que atuam na Educação de Jovens e Adultos (EJA). É fruto da inquietação das pesquisadoras durante experiência no Mestrado Profissional de Educação de Jovens e Adultos (MPEJA), ao refletir sobre as contribuições para o processo inclusivo nas escolas, na referida modalidade, bem como as práticas em defesa do direito à educação para todos. A problemática abordada nesse artigo foi sobre o olhar que os mestrandos têm sobre a inclusão no ambiente escolar na EJA. O objetivo geral foi investigar a visão que os discentes do Mestrado Profissional, oferecido por uma universidade pública baiana, têm sobre a inclusão no ambiente escolar da EJA. Os objetivos específicos foram: discutir a educação inclusiva, analisando a inclusão no ambiente escolar da EJA; elencar as atividades pedagógicas desenvolvidas para tais grupos na EJA pelos mestrandos na perspectiva da educação inclusiva. A metodologia utilizada foi a abordagem qualitativa com pesquisa de campo, envolvendo 22 sujeitos, e uso de questionário para coleta das informações. Os resultados apontam que a investigação viabiliza o suporte teórico necessário ao mestrando, que deseja fortalecer a sua prática educativa no ambiente escolar da EJA. Conclui-se também que o uso de práticas inclusivas fortalecerá a construção da autonomia e a emancipação dos sujeitos em busca da garantia de direitos a todos.
\end{abstract}

Palavras-chave: educação inclusiva; formação acadêmica; educação de jovens e adultos.

Introdução

O resultado das discussões acerca da inclusão, na atualidade, aponta caminhos para a construção de uma sociedade verdadeiramente para todos, indistintamente. Apesar de a temática ser discutida desde os primórdios, constitui-se ainda um desafio. Essas reflexões enriquecem tanto a educação inclusiva, como a formação de uma cultura dos direitos humanos. Entendemos a inclusão escolar como um projeto inovador, embora permeado de complexidade, uma vez que demanda a gestação de uma mentalidade inclusiva, perpassando por questões subjetivas.
Julimar Santiago Rocha

Universidade do Estado da Bahia (UNEB)

rocha.juli12@hotmail.com Débora Regina Oliveira Santos Universidade do Estado da Bahia (UNEB)

deborareginaos@hotmail.com Patrícia Carla da Hora Correia Universidade do Estado da Bahia (UNEB)

patricia@inclusaodahora.com.br 
O paradigma da inclusão defende o direito a educação para todos, bem como celebra a diversidade humana e as diferenças individuais como meios de contribuir para a formação cidadã. Sabemos da necessidade e da urgência de se enfrentar o desafio da inclusão escolar e colocar em prática os meios pelos quais ela verdadeiramente se efetive. O que nos moveu para esse estudo foi a inquietação durante a experiência como alunas e/ou professoras do Mestrado Profissional de Educação de Jovens e Adultos (MPEJA) ao refletirmos sobre as nossas contribuições para o processo inclusivo nas escolas, em particular, as que ofertam a Educação de Jovens e Adultos (EJA).

A referida inquietação acerca do processo inclusivo nas escolas de EJA nos conduziu a questionar: qual o olhar que os alunos(as) do MPEJA, turma 4, têm sobre a inclusão no ambiente escolar da EJA? O nosso principal objetivo foi investigar a visão que os referidos discentes possuem sobre esse tema. Os objetivos específicos traçados foram: discutir a educação inclusiva analisando a inclusão no ambiente escolar da EJA; identificar os grupos considerados como inclusão no espaço escolar em que os mestrandos do MPEJA estão inseridos e elencar as atividades pedagógicas desenvolvidas para tais grupos na EJA, pelos mestrandos na perspectiva da educação inclusiva.

Respaldamos teoricamente o artigo, tendo como principais autores: Rodrigues (2006) que discute a inclusão na atualidade lançando sementes para a verdadeira inclusão escolar; Sassaki (2002) que aponta o cuidado com a linguagem para a construção de uma verdadeira sociedade inclusiva; Dantas (2016) que trata do MPEJA e da formação do professor da EJA.

O trabalho está organizado de modo que a introdução revela a problemática central e a justificativa do trabalho. Em seguida, o percurso metodológico e caracterização dos sujeitos da pesquisa. Depois uma primeira reflexão sobre a educação inclusiva no ambiente escolar da EJA. Posteriormente, abordamos a formação dos mestrandos do MPEJA para o fortalecimento da inclusão escolar na EJA. Na última seção intitulada "O processo de insclusão na EJA sob a ótica dos mestrandos", discutimos os resultados obtidos através da pesquisa. Finalizamos com considerações, seguidas pelas referências do estudo. 


\section{Percurso metodológico}

A trajetória metodológica escolhida para esta investigação foi a abordagem qualitativa de pesquisa, a pesquisa de campo enquanto procedimento técnico e o questionário para coleta de dados. Adotamos a pesquisa qualitativa por concordar com Minayo (2003) quando afirma que este tipo de estudo busca informações mais subjetivas, considerando as especificidades dos sujeitos e do universo da investigação. Ela possibilita descobrir o porquê das coisas e dos fenômenos, aprofundando-se no significado das ações e relações humanas.

Quanto ao procedimento técnico escolhemos a pesquisa de campo que se caracteriza pelas investigações em que, além da pesquisa bibliográfica e(ou) documental, se realiza coleta de dados junto as pessoas (FONSECA, 2002). Tem como objetivo conseguir informações e(ou) conhecimentos acerca de um problema, para o qual se procura uma resposta. A pesquisa de campo permite o pesquisador conhecer a realidade empírica por meio das concepções teóricas que embasam o estudo. Percorre três fases: pesquisa bibliográfica sobre o objeto em questão, definição da técnica para a coleta de dados, e a escolha dos sujeitos.

No intuito de aprofundarmos nosso conhecimento acerca da inclusão escolar e da EJA elegemos como lócus da pesquisa o Programa de Pós-Graduação na modalidade de Mestrado Profissional em Educação de Jovens e Adultos (MPEJA), buscando elucidar a seguinte questão de investigação: qual o olhar que os alunos do MPEJA, turma 4 têm sobre a inclusão no ambiente escolar da EJA?

Esse Programa Pós-Graduação na modalidade de Mestrado Profissional da Universidade do Estado da Bahia (UNEB) foi aprovado com nota 3 pela Coordenação de Aperfeiçoamento de Pessoal de Nível Superior (Capes) no ano de 2012. Começou a funcionar em agosto de 2013, sendo o primeiro Mestrado Profissional em EJA do Brasil. Atualmente foi avaliado com nota 4.

O programa tem como objetivo geral a qualificação profissional de recursos humanos com capacidade científica, didático-pedagógica, técnica, política, e ética para atuar no ensino, na pesquisa, na extensão e na gestão na área da EJA, atendendo às peculiaridades desse campo e aos novos paradigmas educacionais para esta área. Possui um currículo diversificado distribuído em três Áreas de Concentração, que podem gerar diversas linhas de 
pesquisa, a saber: Educação, Meio Ambiente e Trabalho; Formação de Professores e Políticas Públicas; Gestão Educacional e Novas Tecnologias da Informação e da Comunicação.

Até o presente momento, aconteceram sete processos seletivos de alunos para a constituição das turmas. Esta pesquisa escolheu como público-alvo os(as) mestrandos(as) da turma 4, constituída por 33 alunos(as). Esses estudantes são oriundos da capital baiana (Salvador) e dos municípios do interior da Bahia. A sua maioria é professor(a) que assume algumas funções como: docente, diretor(a) escolar, e coordenador(a) pedagógico(a). Alguns atuam em outras áreas, assumindo a função de jornalista, advogado(a), artista plástico(a) e assistente social.

Para responder à questão inicial e coletar os dados da investigação escolhemos aplicar um questionário. Segundo Marconi e Lakatos (2006), o questionário é um instrumento de coleta de dados formado por uma lista de perguntas abertas, fechadas ou de múltipla escolha, que possibilita o informante responder por escrito sem precisar da presença do pesquisador. Assim, acreditamos que este instrumento foi a forma mais viável dado que os sujeitos da pesquisa moram em diversos municípios.

Destacamos que as perguntas buscaram corresponder aos objetivos traçados pelo estudo. O questionário foi construído no Google forms, contendo perguntas fechadas e abertas, e enviado por e-mail para 31 mestrandos, já que 2 discentes são as pesquisadoras deste estudo. Dos 31 questionários distribuídos, obtivemos somente a devolução por 22 discentes. Com o intuito de garantir o sigilo, a identidade dos sujeitos não será divulgada. Os discentes serão nomeados pela letra $\mathrm{M}$ acrescida de um algarismo.

\section{Educação inclusiva no ambiente escolar da EJA}

A educação afirma-se como um direito social a partir da Constituição de 1988, conhecida como Constituição Cidadã. Em seu art. 205 traz que: "A educação, direito de todos e dever do Estado e da família, será promovida e incentivada com a colaboração da sociedade, visando ao pleno desenvolvimento da pessoa, seu preparo para o exercício da cidadania e sua qualificação para o trabalho." (BRASIL, 1988) Nesse contexto, encontramos de forma explícita 
o dever do Estado e o direito de todas as pessoas, sem qualquer distinção, à educação.

Na década de 1990, encontramos vários movimentos para a garantia da educação para todos, inclusive com iniciativas de caráter internacional, como a Conferência Mundial de Educação para Todos, em Jomtien, na Tailândia, em 1990. Durante a referida conferência houve o lançamento da Declaração Mundial da Educação para Todos que preconiza a universalização da Educação Básica para todos, a redução do analfabetismo do adulto para a metade do índice da década e, a eliminação das diferenças existentes entre os gêneros.

Outros documentos que asseguram o direito da educação para todos os sujeitos derivam dela, como por exemplo, a Declaração de Salamanca, de 1994. A Lei de Diretrizes e Bases da Educação (LDB), aprovada em fins de 1996, acompanhada posteriormente das Diretrizes Curriculares Nacionais, através do Parecer $n^{\circ}$ 11/2000, reforçam o direito à Educação de Jovens e Adultos. Com o objetivo de garantir os direitos preconizados, emergem políticas públicas que orientam a melhoria da qualidade da educação a partir dos princípios da autonomia, da colaboração, da participação, da igualdade de oportunidades e da inclusão social.

A partir de 2000, o princípio inclusivo torna-se um imperativo em todo e qualquer sistema de ensino, passando a organizar a sociedade. Em 2011, a antiga Secretaria de Educação Continuada, Alfabetização e Diversidade (Secad), torna-se: Secretaria de Educação Continuada, Alfabetização, Diversidade e Inclusão (Secadi). Tem como objetivo contribuir para o desenvolvimento inclusivo dos sistemas de ensino voltados à valorização das diferenças e da diversidade, à promoção da educação inclusiva, dos direitos humanos e da sustentabilidade socioambiental, visando a efetivação de políticas públicas transversais e intersetoriais.

Ao falarmos sobre inclusão faz-se necessário imaginar quantos olhares seriam necessários para captar a complexidade deste tema. De acordo com Acorsi (2010, p. 121) "ao tomarmos a inclusão como o assunto do momento, é interessante pensarmos sobre ela, buscando suas possíveis significações para então operar com as representações que ela carrega". Sendo a diversidade um fator inerente a todos os seres vivos, falar de inclusão conduz-nos à reflexão sobre este conceito que, embora aceito pela maioria das pessoas como aquilo que deve ser, suscita sempre muitas dificuldades na sua implementação. 
O conceito que adotamos de inclusão nos remete para a garantia de direitos a todos os indivíduos indistintamente, respeitando as suas singularidades e diversidades. Defendemos a igualdade de oportunidades para todos, de forma a promover o respeito mútuo e de eliminar as barreiras impostas pela sociedade, para que todos os indivíduos possam participar dela ativamente. A nomenclatura que utilizamos nos conceitos "[...] expressa, voluntariamente ou involuntariamente, o respeito ou a discriminação em relação às pessoas[...]" (SASSAKI, 2002, p. 5) Portanto, a implantação de uma sociedade inclusiva passa também pelo cuidado com a linguagem e com os conceitos utilizados.

Todos são convocados a fazer parte da escola, incluindo nesse universo, as pessoas com deficiência, todas as outras singularidades relacionadas à etnia, orientação sexual, opção religiosa, classe social, entre outras. Na educação inclusiva, o conviver com as multiplicidades dos sujeitos além de enriquecer o aprendizado, oportuniza o exercício do respeito mútuo, da convivência pacífica, e do aproveitamento dessas diferenças para melhorar nossa sociedade.

Para Rodrigues (2006), a inclusão em educação seria antes de qualquer coisa rejeitar a exclusão de todo e qualquer aluno da comunidade escolar. A inclusão escolar implica, portanto, em uma mudança de perspectiva educacional, pois não atinge apenas alunos com deficiência e os que apresentam dificuldades de aprender, mas os demais, para a garantia de seus direitos em busca da igualdade.

Sem dúvida, a razão mais importante para o ensino inclusivo é o valor social da igualdade. Ensinamos os alunos, através do exemplo, que, apesar das diferenças, todos nós temos direitos iguais. Em contraste com as experiências passadas de segregação, a inclusão reforça a prática da ideia de que as diferenças são aceitas e respeitadas. (STAINBACK, 1999, p. 26-27)

Ao falarmos de inclusão escolar neste estudo nos referimos a um direito inalienável para todos os sujeitos, em todos os segmentos de ensino e modalidades, garantindo a esses o exercício pleno da cidadania. O desafio da contemporaneidade encontra-se, portanto, na efetivação das políticas, principalmente quando nos referimos a uma modalidade de ensino que sempre esteve à margem dos investimentos do governo. Ireland (2016) aponta para a complexidade do fenômeno da invisibilidade que afeta os sujeitos que compõem 
a EJA, sugerindo que essa modalidade é a que enfrenta maiores desafios para a garantia do direito à educação.

Dentro dessa população educacionalmente invisível há vários segmentos que sofrem de uma marginalização e de uma vulnerabilidade que os fazem mais invisíveis ainda. Embora seja possível elencar uma lista desses segmentos, aqui citamos três exemplos que consideramos emblemáticos: as pessoas com deficiência, as pessoas em situação de privação e restrição de liberdade e as pessoas idosas. (IRELAND, 2016, p. 217)

De acordo o pensamento do referido autor, nos deparamos com o seguinte questionamento: como desenvolver atividades inclusivas na EJA com sujeitos tão diversos que a compõem, de forma a dar visibilidade a todos, sem distinção? No próximo tópico abordaremos a importância da formação docente para o fortalecimento da EJA e como o MPEJA vem colaborando nesse processo.

\section{Formação dos mestrandos do MPEJA para o fortalecimento da inclusão escolar na EJA}

A formação docente para os professores que atuam na EJA nunca se constituiu uma pauta emergente nas políticas públicas brasileiras. Contudo, é visível a necessidade desse tema no campo de debate na área educacional do mundo contemporâneo. Cotidianamente, os professores são convidados a enfrentar os desafios do ambiente escolar, sendo pressionados por mudanças nas práticas pedagógicas para atender às peculiaridades dos sujeitos que compõem esta modalidade de ensino. Acreditamos que a formação docente colabora com este profissional no sentido de possibilitar uma investigação sobre as características deste universo plural. De acordo com esse pensamento, Dantas (2016, p. 131) afirma:

A preocupação com a educação e formação de professores vem aparecendo como uma questão crucial no mundo contemporâneo pressionado pelas demandas e necessidades dos grupos sociais que compõem a sociedade, que clamam por melhores condições de trabalho e qualidade de vida, por acesso à escolaridade gratuita, por ascensão no mundo do trabalho. A pauta emergente nas discussões é a educação de jovens e 
adultos e o cenário da formação de professores que atuam nesta modalidade educativa.

Para a referida autora, precisamos debruçar nosso olhar para a EJA como também refletirmos sobre o processo formativo deste profissional que lida com vários grupos sociais que buscam, sobretudo, qualidade de vida. Pensar nesta perspectiva requer compreender a diversidade que compõe o cenário da EJA: homens, mulheres, jovens, adultos, idosos, mães, filhos, avós, trabalhadores, desempregados, donas de casa, itinerantes, negros, índios, ciganos, pessoas com deficiências, sem-terra, homossexuais, bissexuais, heterossexuais, católicos, espíritas, evangélicos, candomblecistas e demais sujeitos plurais.

É partindo deste contexto que ressaltamos que o sucesso do aluno parte da compreensão, por parte do professor, de que as turmas são heterogêneas e que, nessa desigualdade se promove um aprendizado significativo. Assim, surge a importância de colocarmos em pauta na estrutura formativa do profissional o estudo da educação inclusiva como viés para o fortalecimento da EJA. Desta forma se possibilitará ao docente lidar com as diferenças e atender às necessidades de todos os sujeitos do universo escolar.

\footnotetext{
Os recursos físicos e os meios materiais para a efetivação de um processo escolar de qualidade cedem prioridade ao desenvolvimento de novas atitudes e formas de interação, na escola, exigindo mudanças no relacionamento pessoal e social e na maneira de se efetivar os processos de ensino e aprendizagem: inclusão! (MANTOAN, 1997, p. 8)
}

Nessa direção, partimos da perspectiva de que o professor precisa educar para humanização. Humanizar as pessoas do ambiente educativo para a construção de uma sociedade mais justa, igualitária e democrática. Dessa forma, na condução das assim como, temas direcionados para a viabilização da inclusão escolar.

Com o objetivo de atender a esta demanda foi que se efetivou a política pública de formação para este profissional através da implantação, no ano de 2013, do Programa de Pós-Graduação na modalidade de Mestrado Profissional em Educação de Jovens e Adultos (MPEJA), da UNEB, sendo pioneira no Brasil. Desenvolvido no Departamento de Educação (DEDC) - campus I, com a carga horária de 840 horas, nos turnos vespertino e noturno, abrange 
três áreas de concentração: Educação, Trabalho e Meio Ambiente; Formação de Professores e Políticas Públicas; Gestão Educacional e Novas Tecnologias.

Para Dantas (2016, p. 143) "O MPEJA visa a produção de conhecimentos, a atualização permanente dos avanços da ciência e das tecnologias, a formação e o aperfeiçoamento de profissionais na área da educação de jovens e adultos, atendendo às demandas sociais e profissionais". Segundo a autora, o referido mestrado tem como objetivo qualificar profissionais da área para atender às especificidades da EJA, investindo na capacidade científica, pedagógica, metodológica, política, técnica e ética, potencializando sua atuação enquanto professor, gestor, formador ou pesquisador.

A oferta de vagas para a quarta turma aconteceu em 2016.2, oferecendo 33 vagas. A curiosidade desta pesquisa é saber os olhares dos mestrandos que compõem esta turma sobre inclusão escolar, refletindo desta forma o propósito estabelecido pelo programa e os desafios enfrentados pelos sujeitos que vivenciam o universo escolar da EJA.

Ressaltamos que a matriz curricular do programa comporta vários componentes na perspectiva inclusiva, mas, neste estudo enfatizamos o componente curricular "Cidadania, Inclusão e Ética na Educação de Jovens e Adultos" com a carga horária de 45 horas e 3 créditos, e que compõe o núcleo comum. A ementa faz referência à educação inclusiva ao tratar das políticas públicas de inclusão da minoria; medidas legais e políticas adotadas para melhoria do processo ensino-aprendizagem; análise das mazelas enfrentadas pela educação, dentre elas a "exclusão" e a evasão escolar. No próximo tópico faremos uma discussão sobre a temática inclusão escolar sob a ótica dos mestrandos do MPEJA - turma 4.

\section{O processo de inclusão na eja sob a ótica dos mestrandos}

Analisamos, nesta seção, os resultados da pesquisa sobre a visão que os alunos do MPEJA, turma 4, têm sobre a inclusão no ambiente escolar da EJA. Para isso refletimos sobre as informações coletadas através das perguntas dos questionários com base na fundamentação teórica mencionada nos tópicos anteriores. Os sujeitos não serão nomeados por questão ética, sendo identificados pela letra maiúscula M seguida de um algarismo de forma crescente. As perguntas foram agrupadas de modo a 
formar três temáticas: Inclusão escolar na EJA; Procedimentos didáticos na EJA na perspectiva da educação inclusiva, e, Contribuições do MPEJA no processo inclusivo.

A primeira temática parte do pressuposto da inclusão como princípio para todos indistintamente, refletindo tanto sobre o seu conceito, como também quais grupos e pessoas eles identificam como partícipes ativos no espaço escolar onde atuam. Na segunda temática, tratamos dos Procedimentos didáticos na EJA na perspectiva da educação inclusiva, na qual buscamos compreender como os sujeitos desenvolvem trabalhos na referida perspectiva de forma a oportunizar uma educação para todos os sujeitos que compõem a EJA. E, finalmente e não menos importante, abordamos a temática Contribuições do MPEJA no processo inclusivo, na qual coletamos dos sujeitos aspectos relacionados à sua formação como mestrandos em EJA, e que contribuições o programa traz para uma (re)construção do seu conceito de inclusão no ambiente escolar da EJA.

Para iniciarmos nossa discussão, e com o intuito de investigarmos a visão dos discentes do MPEJA sobre o tema em estudo, buscamos na questão inicial o entendimento dos mestrandos referente à inclusão escolar na EJA. Para aprofundarmos esta reflexão utilizaremos algumas falas que representam o coletivo dos sujeitos.

A princípio trazemos para análise dois termos bem pertinentes, presentes no depoimento do M4: acolhimento e respeito. Segundo a referida mestranda, inclusão "é acolher o sujeito, independente de deficiências, credo, ou gênero, na escola, e garantir sua permanência, além de respeitar as especificidades". O sujeito trata a inclusão como acolhimento independente de quaisquer características diferenciada que o aluno tenha. Seu conceito aponta também para o respeito, elemento necessário para a convivência pacífica entre as pessoas.

Há uma concordância dessa fala com Rodrigues (2006), que aborda a inclusão em educação como meio de rejeitar a exclusão de qualquer aluno da comunidade escolar. E que não seja restrita apenas a alunos com deficiência, mas garanta a todos os sujeitos o acolhimento, acesso e permanência.

O conceito que adotamos sobre inclusão neste trabalho difere de integração, uma vez que a integração pressupõe a participação numa estrutura com valores próprios à qual o aluno, seja ele quem for, precisa se adaptar. Na inclusão, a sociedade se adapta para poder incluir em seus sistemas sociais todos os indivíduos. O aluno M12 
traz sua contribuição quando fala da reestruturação da unidade escolar de forma a garantir o direito da educação para todos:

O termo inclusão é, muito amplo, porém pensar inclusão na EJA é adequar a UEE pra atender às necessidades específicas desses educandos quais sejam o direito ao acesso e permanência através de dinâmicas de ensino e aprendizagem, currículo, material adequado à sua idade, organização do tempo escolar, e sobretudo a valorização do seu contexto (M12).

Não seria o indivíduo quem se molda, mas a escola que se prepara para atendê-lo, levando em consideração aspectos estruturais, pedagógicos e culturais, perpassando pelas atividades escolares, metodologia, currículo, organização do tempo e valorização da cultura dos indivíduos que compõem o universo escolar. O conceito do mestrando está em harmonia com a inclusão que solicita das comunidades escolares que se adequem para atender os educandos.

Ressaltamos também que o olhar do M8 condiz com olhar para a EJA como uma modalidade inclusiva que precisa sair da invisibilidade (IRELAND, 2016) e mostrar todo o potencial dos sujeitos que a integram para a construção de conhecimentos. Aborda também sobre a convivência para a construção de saberes coletivos através de uma proposta pedagógica inclusiva.

O conceito de inclusão na EJA acaba se confundindo com a sua própria essência quando se recomenda a elaboração de uma proposta pedagógica inclusiva, onde o objetivo maior dessa modalidade de ensino é a construção de saberes coletivos, envolvendo os educadores e educandos a partir das características do coletivo, promovendo um intercâmbio de conhecimentos (M8).

O sujeito da pesquisa aponta a proposta pedagógica como fundamental para a construção de uma escola inclusiva, sendo o maior objetivo a construção de saberes respeitando as características tanto individuais quanto coletivas. Esse instrumento deve promover a socialização de conhecimentos, bem como considerar as especificidades e saberes dos sujeitos que estão na EJA.

Após a análise do conceito de inclusão dos discentes do MPEJA, questionamos sobre pessoas e(ou) grupos que consideram incluídos no espaço escolar em que atuam, partindo do pressuposto da escola como um espaço para todos. Esse questionamento remete à questão da convivência com o outro como uma condição essencial 
para a vida em sociedade. Propiciou nossa identificação de quem são as pessoas que são visualizadas como integrantes do processo que se pensa inclusivo no ambiente educativo.

Citaram pessoas e ou grupos que consideram incluídos, 32\% dos sujeitos: mulheres, homens, jovens, adultos, idosos, negros, indígenas, analfabetos, homossexuais, pessoas com deficiência, pessoas com problemas psicológicos, e com dificuldades de aprendizagem, desempregados, mães e pais que levam seus filhos para a escola, alunos do campo, trabalhadores rurais ou filhos de trabalhadores rurais. Os mestrandos entendem a inclusão a partir de uma ótica de compreensão das diferenças, tendo no respeito às especificidades a garantia da liberdade, autonomia e igualdade de direitos. Os grupos que citam perpassam pela cultura, etnia, faixa etária, gênero, condição de letramento, localização geográfica, como também por questões específicas vivenciadas na EJA, como as mães que não têm com quem deixar seu filho. A riqueza de detalhes ao elencar os grupos aponta para um olhar não normalizador, mas que consegue ver as individualidades na coletividade.

Responderam como "todos", 10\% dos mestrandos, nos levando a indagar quem são os sujeitos que cabem nesse todo, e 5\% responderam "nenhum". Através destas falas percebemos a necessidade de um conceito mais representativo por parte dos mestrandos sobre quais são as pessoas ou grupos que compõem a educação inclusiva escolar, pois, se generalizarmos como respostas "todos" ou "nenhum" estamos também reproduzindo práticas excludentes na medida em que não pontuamos quem são esses sujeitos. Com essa generalização, não pensaremos em encaminhamentos para atender às necessidades destes sujeitos. Desta forma, as atividades pensadas pelas escolas contemplarão todas as pessoas de igual maneira sem respeitar as diferenças existentes entre os alunos.

Apontaram que são incluídos apenas os chamados "normais" (M13), o equivalente a 10\% dos sujeitos, e que "se aproximam mais do padrão, os que dão menos trabalho para aprender e possuem mais autonomia para participar das atividades propostas" (M3). Entendemos que o conceito de normalidade é uma imposição cultural que exclui a muitos. Quando consideramos um padrão de normalidade a culpa fica no sujeito que não se adequa. Gentili (2001) aponta que a invisibilidade é a marca mais visível dos processos de exclusão neste milênio que se inicia. Exclusão que acontece com o olhar seletivo, normalizador que oculta as individualidades. 
Apontaram especificamente os negros como pessoas incluídas no espaço escolar apenas 5\% dos mestrandos, 15\% trouxeram apenas os alunos com deficiência. Os demais estudantes, 23\% responderam à pergunta, mas, não elencaram pessoas e(ou) grupos que consideram incluídos na escola que atua. No senso comum, muitos atribuem a inclusão exclusivamente às pessoas com deficiência, deixando à margem outros sujeitos.

Analisamos a categorização acima com base na análise de Sassaki (2002) que aponta o uso da linguagem como necessária para a implantação de uma sociedade inclusiva. Vivemos um período de mudanças paradigmáticas que perpassa também pela busca por uma linguagem que traduza a realidade. Entendemos que a linguagem utilizada expressa (in)voluntariamente a forma como concebo a inclusão, sendo também importante instrumento de luta política que pode manter ou modificar uma imagem negativa de determinado indivíduo e(ou) grupo social.

A forma como nos referimos a grupos ou pessoas pode expressar, respeito ou discriminação. Quem são os indivíduos que cabem na categoria "todos"? A quais "negros" a mestranda se refere? Porque não conseguimos categorizar pessoas e(ou) grupos incluídos no espaço escolar?

Dantas (2016) problematiza sobre a EJA e a formação do professor, uma vez que esse profissional trabalha com vários grupos sociais, necessitando, portanto, compreender a diversidade que compõe o cenário dessa modalidade. Consideramos que o sucesso da aprendizagem do aluno perpassa pela compreensão do professor sobre a heterogeneidade de suas turmas. Necessita de um olhar que não normalize e nem oculte as diferenças. Esse olhar precisa ser o catalisador na hora do planejamento e execução das atividades didáticas. E essa será a temática a ser discutida a seguir.

Com o objetivo de compreendermos como os sujeitos desenvolvem trabalhos com perspectiva inclusiva na EJA, de forma a oportunizar uma educação para todos os sujeitos que a compõem, solicitamos que elencassem atividades pedagógicas desenvolvidas para as pessoas e(ou) grupos que tinham apontados no questionamento anterior.

Acreditamos que não basta simplesmente apropriarmos do conceito de inclusão e definirmos as pessoas e grupos incluídos no ambiente escolar. Precisamos ir além disso. Necessitamos contemplar na proposta pedagógica da escola, no planejamento da aula, no 
currículo e, sobretudo, na prática pedagógica do professor da EJA atividades que favoreçam o fortalecimento de práticas inclusivas.

Analisaremos a seguir se as atividades propostas nas escolas onde os mestrandos estão inseridos caminham por esse viés. Cerca de $70 \%$ dos sujeitos da pesquisa não apontam com clareza as atividades pedagógicas que desenvolvem e(ou) executam em sala de aula. Apenas 30\% evidenciam o respeito às especificidades dos alunos: "metodologias diferenciadas, dando mais atenção àqueles que demonstrem mais necessidades para aprender" (M15); "atividades que tenham significado, valorizando as características do grupo, desvelando significados nas atividades aplicadas (M19)". Outro aponta a afetividade como uma estratégia necessária: "Desenvolvo uma relação de proximidade e afetividade com os alunos, permitindo compreender melhor o universo onde os mesmos estão inseridos, a fim de promover uma melhor interação com os conteúdos e projetos desenvolvidos na escola" (M22).

Das atividades citadas pelos sujeitos, podemos elencar: trabalho em equipe, ações educativas que envolvem toda a escola, debates e seminários pautados na etnia e miscigenação do povo brasileiro, prática da leitura, desenvolvimento da oralidade e da comunicação, e atividades práticas dentro e fora da escola, como aulas em laboratórios, discussões sobre cidadania e problemas sociais.

Consideramos a necessidade de buscar práticas e atividades na EJA que oportunizem a construção do conhecimento pelos alunos, trazendo para a sala de aula temas emergentes e necessários para a formação da cidadania. Dessa forma cabe aos professores a pergunta: o que ensinar? Como e qual sujeito quero verdadeiramente formar? Cabe a reflexão também sobre a escolha das metodologias. Elas precisam exercitar a interação, as diferentes habilidades e os conhecimentos prévios trazidos pelos alunos. Analisar continuamente a sua prática pedagógica em comunhão com a realidade que o norteia, com as características dos sujeitos, com as transformações sociais e, que saibam refletir sua prática.

Com base nas respostas anteriores, concluímos que tanto os conceitos de inclusão, como a percepção sobre os grupos e suas singularidades, e como o desenvolvimento de atividades pedagógicas na perspectiva da educação inclusiva na EJA, ainda se encontram difusos. Alguns já mostram avanços na visão de inclusão, outros ainda discorrem sobre suas dificuldades para atender a todos, e não 
deixam claro seu posicionamento, ficando na superfície, no campo periférico da discussão, sem maior aprofundamento ou amplitude.

Passamos então a avaliar a visão que os discentes da turma 4 tem sobre a inclusão no ambiente escolar da EJA, discutindo como o MPEJA contribuiu ou não para a re(construção) do conceito deles no ambiente escolar da EJA.

De modo geral, percebemos que o referido programa vem contribuindo na reelaboração desse conceito, impactando a vida pessoal, acadêmica e profissional dos sujeitos envolvidos na pesquisa. Entretanto, no tocante ao conceito de inclusão no ambiente escolar notamos que a opinião dos mestrandos diverge conforme dados a seguir. 73\% disseram que sim; 4\% apontaram sim, mas, precisa da continuidade deste estudo perante o percurso do curso; 14\% sinalizaram não e 9\% não opinaram por não atuar no ambiente escolar.

Evidenciamos que 73\% dos alunos afirmam que o MPEJA vem contribuindo para a reconstrução do seu conceito de inclusão no ambiente escolar da EJA e apontam como este processo está se constituindo. Trazemos as falas de dois mestrandos que vêm ilustrar o sujeito coletivo de tal afirmativa:

O programa de mestrado através das disciplinas e interação com colegas, seminários, palestras e outras abordagens têm contribuido para um olhar diferenciado a respeito do processo de inclusão na educação e principalmente no que tange ao aluno da EJA no ambiente escolar. O meu olhar hoje é diferente do que eu tinha anteriormente. O meu modo de

O MPEJA tem contribuído para a reconstrução de meu conceito de inclusão da EJA, principalmente na compreensão de que esses educandos são sujeitos de direitos e que independente dos motivos que os afastaram da UEE eles devem encontrar um ambiente de aprendizagem que os respeite em todos os aspectos físicos, pessoais, temporais, cognitivos e afetivos. Também a desconstrução de que a "culpa" pelo fracasso escolar está sempre no aluno (M 12).

temporais, cognitivos e afetivos. Também a desconstrução de que a "culpa" pelo fracasso escolar está sempre no aluno (M 12).

As falas dos(as) alunos(as) reforçam a validade do objetivo do programa, quando se propõe qualificar profissionais para atender às peculiaridades da Educação de Jovens e Adultos, fortalecendo 
esses sujeitos no universo em que atuam. (DANTAS, 2016) Dessa forma, reforçamos a percepção da importância do investimento no campo da pesquisa, na prática pedagógica, na formação docente, e na reflexão política, social e ética. Segundo os pesquisados este processo vem se consolidando através das discussões realizadas nas disciplinas do curso; nas reflexões diárias nesse processo de formação de maneira individual e coletiva; no incentivo à pesquisa neste campo de discussão; na interação com os colegas; na participação dos eventos acadêmicos; no diálogo da temática com as áreas do conhecimento, articulando com especificidades dos sujeitos jovens e adultos.

Vale destacar que uma mestranda registrou a contribuição do MPEJA para a reconstrução do seu conceito sobre inclusão no ambiente escolar da EJA, entretanto, apontou a necessidade da continuidade nos estudos e aprofundamento desta temática durante o curso. Concordamos com este pensamento, pois, este campo de debate é complexo devido à subjetividade do universo e dos sujeitos envolvidos na unidade escolar.

A expectativa é que esse saber seja ampliado ao longo do curso. Até o momento, a principal contribuição foi o aumento das dimensões de entendimento sobre a inclusão. Isto é, pensar inclusão não apenas numa perspectiva das deficiências fisico motoras e intelectuais, mas contextualizá-la numa perspectiva social, cultural e econômica (M 15).

Pensar em inclusão é extrapolar a ideia que associa o conceito às pessoas com deficiência. É abordar questões epistemológicas, políticas, sociais, culturais e educacionais, por isso, a referida aluna traz para a discussão a importância de um tempo maior de estudo e aprofundamento para a reconstrução e consolidação deste conceito.

Divergente das opiniões anteriores 14\% dos sujeitos da pesquisa declararam que o MPEJA não vem contribuindo para a reconstrução do seu conceito em pauta. A fala de M3 deixa clara tal afirmativa.

Para mim está sendo difícil essa reconstrução porque a forma como a disciplina foi organizada não trabalha com a EJA. Traz muitas questões de crianças e adolescentes. Até porque o sujeito "normal" da EJA já é um excluido, e eu gostaria de ter mais propriedade para trabalhar primeiro com esse sujeito, que é a maioria, falando numericamente. Assim, acho que o trabalho com os deficientes aconteceria de maneira mais natural e não da forma que vem sendo, parecendo que inclusão é só de pessoas com deficiências (M 3). 
A contribuição de M3 deixa evidente sua necessidade em se apropriar do conceito de inclusão escolar no universo da EJA. Para ela, a disciplina "Cidadania, Inclusão e Ética" deixou lacunas em sua formação por focar mais no aluno do público infantil e adolescente e nas pessoas com deficiência. Afirma que o estudante da EJA já é naturalmente excluído da sociedade, por isso ressalta a importância de investir na formação dos mestrandos para saber lidar com as necessidades deste público. Condizente com este pensamento tanto Ireland (2016) quanto Dantas (2016) contribuem com esta discussão na medida em que o primeiro autor chama atenção para a importância de darmos visibilidade aos sujeitos que se constituem minoria e a segunda autora quando defende a necessidade da formação continuada docente para o fortalecimento da EJA.

Acreditamos que a formação dos mestrandos do MPEJA deve priorizar a reflexão dos sujeitos plurais que compõem o ambiente escolar da EJA. Neste sentido, pensar em inclusão escolar para esta modalidade de ensino é refletir a identidade desses sujeitos; respeitar seu estilo de aprendizagem; valorizar, na prática pedagógica, sua itinerância pessoal, familiar, social, política e cultural; contemplar os conhecimentos e saberes construídos dentro e(ou) fora da escola; colaborar com o processo de autonomia e emancipação dos alunos, dentre outros. Para tanto, o MPEJA precisa, de fato, investir na formação dos mestrandos no sentido de estimular a pesquisa; incentivar participações nos eventos acadêmicos; permitir que o mestrando observe e reflita a prática pedagógica dos profissionais que atuam na EJA; propor estudos e atividades práticas que reflitam temáticas emergentes.

De modo geral, no tocante a esta pesquisa, segundo a ótica dos mestrandos, turma 4, reafirmamos que o Programa de Mestrado Profissional da Educação de Jovens e Adultos vem contribuindo para a construção ou reelaboração do conceito sobre inclusão no ambiente escolar da Educação de Jovens e Adultos, fortalecendo sua formação pessoal, acadêmica e profissional.

\section{Considerações finais}

Chegamos ao final deste artigo destacando a consolidação da problemática, pois, refletimos sobre inclusão escolar, EJA e o MPEJA. Investigar a visão que os referidos discentes desse Mestrado Profissional têm sobre a inclusão no ambiente escolar 
da EJA permitiu constatar que o investimento realizado na política pública na oferta de um curso de formação Stricto Sensu para os profissionais que atuam na EJA colabora na (re)construção do conceito em pauta, além de fortalecer a prática desses sujeitos que atuam na realidade da qual fazem parte.

Concordamos que os objetivos traçados foram atingidos durante o percurso da pesquisa, na medida em que pudemos investigar a visão dos mestrandos referente à temática; discutir a educação inclusiva, analisando a inclusão no ambiente escolar da EJA; identificar os grupos considerados como inclusão no espaço escolar em que os mestrandos do MPEJA estão inseridos e elencar as atividades pedagógicas desenvolvidas para tais grupos na EJA, pelos mestrandos na perspectiva da educação inclusiva.

A partir da análise das informações cedidas pelos respondentes do questionário ficou evidente que, apesar de alguns mestrandos associarem inclusão apenas a alunos com deficiência, na opinião da maioria, o conceito de inclusão escolar extrapola esse pensamento. De modo geral, os discentes compreendem inclusão como acolhimento, respeito, e, sobretudo, garantia de direitos de todas as pessoas envolvidas no ambiente educativo, que tem como marca singular as diferenças dos sujeitos em prol da conquista da autonomia, emancipação e equidade social.

Com o olhar específico para a EJA este estudo demonstrou que as pessoas ou os grupos incluídos nesta modalidade educativa perpassam pela composição de raça, cor, etnia, gênero, religião, faixa etária, nível de letramento, além das questões peculiares dos jovens e adultos. Notamos a necessidade de um maior aprofundamento dos discentes no sentido de conceituar inclusão e definir as pessoas e/ou grupos considerados incluídos no ambiente escolar. Além da proposição de atividades pedagógicas que contemplem e valorizem a inclusão escolar para a EJA. Essas questões nos remetem a uma reflexão não meramente conceitual, mas, sobretudo, política e social, pois, acreditamos que quando há uma apropriação epistemológica e uma definição clara de conceitos e do que queremos, fica mais viável planejarmos quais caminhos iremos traçar para alcançarmos nossos objetivos.

Essa reflexão não cabe apenas aos mestrandos que atuam como professores, diretores, coordenadores pedagógicos ou pesquisadores. A escola também precisa refletir que tipo de homem, sociedade, aluno quer formar no intuito de ter embasamento para 
construir uma proposta pedagógica inclusiva que abarque toda essa pluralidade existente no ambiente escolar, especialmente da EJA.

Recomendamos aqui o incentivo a novas pesquisas sobre a importância da educação inclusiva no ambiente escolar da EJA, apontando encaminhamentos no investimento da formação dos profissionais que atuam nesta área, assim como, repensando as práticas pedagógicas que contemplam os princípios da educação inclusiva, respeitando as especificidades dos membros que compõem o universo da Educação de Jovens e Adultos.

\title{
The views of students from the Professional Master's Degree in Youth and Adult Education on inclusion in the EJA school environment
}

\begin{abstract}
This study starts from the need to discuss the formation of teachers who work in Youth and Adult Education (EJA). It is the result of the researchers' concern during their experience in the Professional Master's Program in Youth and Adult Education (MPEJA), when reflecting on the contributions to the inclusive process in schools, in that modality, as well as the practices in defense of the right to education for all. The problem approached in this article was about the view that master's students have on inclusion in the school environment in EJA. The general objective was to investigate the view that the Professional Master's students, offered by a public university in Bahia, have about inclusion in the school environment of EJA. The specific objectives were: to discuss inclusive education, analyzing inclusion in the school environment of EJA; list the pedagogical activities developed for such groups in EJA by the master students in the perspective of inclusive education. The methodology used was the qualitative approach with field research, involving 22 subjects, and the use of a questionnaire to collect the information. The results show that the investigation enables the theoretical support necessary for the master's student, who wants to strengthen his educational practice in the school environment of EJA and it is concluded that the use of inclusive practices will strengthen the construction of autonomy and the emancipation of subjects in search of guaranteeing rights for all.
\end{abstract}

Keywords: inclusive education; academic formation; youth and adult education.

\section{Las miradas de los alumnos de Maestría del MPEJA a cerca de la Inclusión en el Ambiente Escolar de la EJA}

Resumen: Este estudio parte de la necesidad de la discusión acerca de la formación de maestros que actúan en la Educación de Jóvenes y Adultos (EJA). Es el fruto de la inquietud de las investigadoras durante su experiencia en la Maestría Profesional de la Educación de Jóvenes y Adultos (MPEJA), al reflexionar sobre las contribuciones para el proceso inclusivo en las escuelas, en la referida modalidad, bien como las prácticas en defensa del derecho a la educación para todos. La problemática abordada en este artigo es sobre la mirada que los estudiantes de maestría tienen a cerca de la inclusión en el 
ambiente escolar en el EJA. El objetivo general fue investigar la visión que los discentes de la Maestría Profesional, ofrecido por una universidad pública bahiana, tienen a cerca de la inclusión en el ambiente escolar en el EJA. Los objetivos específicos fueron: discutir la educación inclusiva analizando la inclusión en el ambiente escolar del EJA, enumerar las actividades pedagógicas desarrolladas para tales grupos en el EJA, por los estudiantes de Maestría en la perspectiva de la educación inclusiva. La metodología utilizada fue el abordaje cualitativa con investigación de campo envolviendo 22 sujetos y el uso de una encuesta para coleta de informaciones. Os resultados apuntan que la investigación viabiliza el suporte teórico necesario al estudiante de Maestría que desea fortalecer a su práctica educativa en el ambiente escolar del EJA. Se concluye también que el uso de prácticas inclusivas fortalecerá la construcción de la autonomía y la emancipación de los sujetos en la búsqueda de la garantía de los derechos a todos.

Palabras clave: educación inclusiva; formación académica; educación de jovenes y adultos.

\section{Referências}

ACORSI, R. Inclusão: (im)possibilidades para a educação. In: LOPES, M. C.; FABRIS, E. H. (org.). Aprendizagem \& inclusão: implicações curriculares. Santa Cruz do Sul: EDUNISC, 2010. p. 177-193.

BRASIL. [Constituição (1988)]. Constituição da República Federativa do Brasil. Brasília, DF: Presidência da República, [2016]. Disponível em: https://www.senado.gov.br/atividade/const/con1988/ CON1988_05.10.1988/art_206_.asp. Acesso em: 30 abr. 2017.

BRASIL. Lei n. ${ }^{\circ}$ 9.394, de 20 de dezembro de 1996. Estabelece as diretrizes e bases da educação nacional. Disponível em: http://www.planalto.gov. br/ccivi103/leis/19394.htm. Acesso em: 30 abr. 2017.

BRASIL. Ministério da Educação. Secretaria de Educação Continuada, Alfabetização e Diversidade. Documento nacional preparatório à VI Conferência Internacional de Educação de Adultos. Brasília, DF: MEC; Goiânia: FUNAPE/UFG, 2009. Disponível em: http://portal.mec.gov. br/index.php?option $=$ com_docman\&view $=$ download\&alias $=10024-$ confitea-6-secadi\&Itemid =30192. Acesso em: 30 abr. 2017

CONFERÊNCIA NACIONAL DE EDUCAÇÃO (CONAE). Construindo o sistema nacional articulado de educação: o plano nacional de educação, diretrizes e estratégias. Documento final. Brasília, DF: Ministério de Educação, 2010b. Disponível em: http:// conae.mec.gov.br/images/stories/ pdf/pdf/documetos/documento_final.pdf. Acesso em: 12 abr. 2017.

DANTAS, T. R. Formação em EJA: o programa de mestrado profissional como uma proposta inovadora de inclusão social. In: DANTAS, T. R.; AMORIM, A.; LEITE, G. de O. Pesquisa, formação, alfabetização e direitos em educação de jovens e adultos. Salvador: Edufba, 2016. Cap. 6. p. 131-149.

FONSECA, J. J. S. Metodologia da pesquisa científica. Fortaleza: UEC, 2002.

GENTILI, P. A exclusão e a escola: o apartheid educacional como política de ocultação. In: GENTILI, P.; ALENCAR, C. (org.) Educar na esperança em tempos de desencanto. Petrópolis: Vozes, 2001. p. 25-44. 
IRELAND, T. D. Todas as modalidades de educação são iguais, mas algumas são mais iguais do que outras: a educação de jovens e adultos como direito humano em debate. In: DANTAS, T. R.; AMORIM, A.; LEITE, G. de O. (org.). Pesquisa, formação, alfabetização e direitos em educação de jovens e adultos. Salvador: Edufba, 2016. p. 205-222.

MANTOAN, M. T. E. Introdução. In: MANTOAN, M. T. E. (org.). A integração de pessoas com deficiência: contribuições para uma reflexão sobre o tema. São Paulo: Memmon, 1997. p. 6-8.

MARCONI, M. de A. e LAKATOS, E. M. Técnicas de pesquisa. 6. ed. São Paulo: Atlas, 2006.

MINAYO, M. C. de S. (org.). Pesquisa social: teoria, método e criatividade. Petrópolis: Vozes, 2003.

RODRIGUES, D. Dez idéias (mal)feitas sobre a educação inclusiva. In: Rodrigues, D. (org.). Inclusão e educação: doze olhares sobre a Educação inclusiva, São Paulo: Summus Editorial, 2006. p.1-16.

SASSAKI, Romeu Kazumi. Terminologia sobre deficiência na era da inclusão. Revista Nacional de Reabilitação, São Paulo, v. 5, n. 25, p. 5-14, mar./abr. 2002.

STAINBACK, S.; STAINBACK, W. Inclusão. Um guia para educadores. Tradução Magda França Lopes Porto Alegre: Artes Médicas Sul, 1999. 